\title{
La conceptualización experta en los diagnósticos judiciales y penales de adolescentes en Montevideo
}

\section{The expert conceptualization in judicial and penal teenagers' diagnoses in Montevideo}

\author{
Carolina González Laurino \\ Doctora en Sociología y Ciencias Políticas (opción Sociología) por la Universidad de Deusto, España. Licenciada en Sociología egre- \\ sada de la Universidad de la República (UdelaR), Uruguay. Licenciada en Trabajo Social por la UdelaR. Docente e investigadora \\ del Departamento de Trabajo Social de la Facultad de Ciencias Sociales de la UdelaR, Montevideo, Uruguay. \\ La investigación se realizó en el marco del proyecto central de dedicación total a la UdelaR y contó con financiamiento de la Comi- \\ sión Sectorial de Investigaciones Científicas (CSIC) de la UdelaR. \\ Correo electrónico: carolsoc@gmail.com
}

\begin{abstract}
Resumen
El artículo analiza el uso conceptual de las ideas de riesgo social y vulnerabilidad, habitualmente utilizados en el campo de la infancia en Uruguay. La investigación está centrada en el área de la justicia penal juvenil y su base empírica se sustenta en el análisis de discurso. La investigación da cuenta del uso de ambos conceptos en los informes sociales judiciales y penales que parecen remitir a una lectura que sugiere distintas respuestas institucionales frente a la misma situación.

Palabras clave. diagnósticos expertos, riesgo social, vulnerabilidad social, justicia juvenil.

Abstract

The article analyzes the conceptual use of the ideas of social risk and vulnerability, commonly used in childhood's field in Uruguay. The research is focused on the area of juvenile justice and its empirical work is based on discourse analysis. The investigation identifies the use of both concepts in the social judicial and penal reports that suggests different institutional answers to the same situation.
\end{abstract}

Key words. expert diagnostic, social risk, social vulnerability, juvenile justice.

\section{Introducción}

La investigación se centra en el análisis del área socio-jurídica de intervención social, entendiendo como tal el campo social que regula la intervención socialmente organizada en el tema de la infracción adolescente, a través del análisis de los discursos expertos institucionalmente adscriptos al sistema judicial y penal. En cuanto al sistema judicial, la investigación se centra en los Juzgados de Adolescentes de Montevideo. En el sistema penal de adolescentes se consideran tanto las intervenciones realizadas por las organizaciones de la sociedad civil habilitadas para la aplicación de medidas no privativas de libertad, como por el Estado, que actúa a través del Instituto de la Niñez y la Adolescencia en Uruguay (en adelante INAU), que se encarga tanto de la implementación de las medidas de sanción privativas de libertad, como de las medidas alternativas a la internación.

Si bien se reconoce el carácter directriz del sistema judicial en el análisis de la conducta infractora protagonizada por los adolescentes y su influencia directa sobre las instituciones responsables de la ejecución de la sanción dispuesta, los expedientes judiciales señalan la receptividad del sistema judicial frente a los planteos expertos surgidos en el contexto institucional del sistema penal, invirtiendo la dirección señalada.

Por este motivo, el análisis que el trabajo propone está centrado en los peritajes expertos realizados en el ámbito penal de adolescentes y las consecuencias que estos discursos tienen en la dilucidación de la responsabilidad en las conductas infractoras. Se plantea, por un lado un análisis de la concepción de 
riesgo social que remite a una concepción positiva del individualismo que atraviesa las descripciones especializadas. Por otra parte, como recurso teórico alternativo, se exploran los supuestos conceptuales de la utilización de la idea de la vulnerabilidad social y la carencia de las protecciones sociales, que si bien describe los mismos fenómenos sociales que la noción de riesgo social, su utilización parece sugerir consecuencias diferentes en el tratamiento de la infracción en contextos de pobreza.

Lejos de la inocencia, el lenguaje utilizado en el tratamiento de los asuntos sociales reconoce concepciones teóricas en su abordaje conceptual, toma postura en las discusiones planteadas y asume las consecuencias prácticas que derivan de su discurso. En este sentido es posible afirmar que los discursos tienen efectos sociales (Berger y Luckmann, 1972)

\section{Consideraciones metodológicas}

Con este propósito, se analizan los discursos que surgen de una muestra aleatoria de cincuenta expedientes judiciales archivados en el año 2009, dado que el trabajo de campo se realiza en ese año, en dos de los cuatro Juzgados de Adolescentes de Montevideo.

La aleatoriedad en el proceso de selección de la muestra estuvo dada en función de los criterios de archivo de los expedientes judiciales, que no guardan estricta relación con el momento de inicio de la tramitación judicial sino con la finalización del proceso. Por este motivo, si bien la mayoría de los expedientes encontrados habían iniciado su tramitación en el año 2009, se encontraron expedientes iniciados en el año 2008, cuya tramitación había sido más larga y compleja.

Si bien no fue posible determinar el total de los expedientes iniciados en el 2009 a través de este procedimiento de búsqueda de expedientes archivados, la muestra incluyó la totalidad de los expedientes archivados durante el segundo semestre del año 2009, por lo que es posible inferir que se trabajó con la mitad de los trámites judiciales finalizados durante ese año.

Mediante el estudio de estos documentos se recupera la palabra de los fiscales, defensores, jueces y peritos (trabajadores sociales y psicólogos) que actúan en el ámbito judicial, tanto los discursos de los expertos que operan en las instituciones que tramitan la punición de los adolescentes: trabajadores sociales, psicólogos y educadores sociales, cuyos informes se incluyen en el proceso de tramitación judicial de la infracción.

La intervención social en el área socio-jurídica se entiende aquí en un sentido amplio, como una forma de intervención en el espacio social con objetivos transformadores, independientemente de la formación disciplinaria de sus operadores. Se denominan operadores sociales a todos los expertos que intervienen en el área socio-jurídica en el campo de la infancia y la adolescencia, considerando específicamente la intervención en relación a la infracción adolescente como ámbito de análisis.

\section{La legislación uruguaya en materia de adolescentes}

En la legislación uruguaya, el Código de la Niñez y Adolescencia aprobado en el año 2004 es el documento que define qué es un adolescente ${ }^{1}$, establece cuál es el sistema experto que interviene en caso de una infracción a la ley penal protagonizada por un adolescente ${ }^{2}$, especifica cuáles son las infracciones a la ley penal ${ }^{3}$, define qué es un "adolescente infractor" ${ }^{\text {", }}$ determina las causas que motivan el inicio de un proceso judicial contra un adolescen-

1 En su artículo $1^{\circ}$ el Código de la Niñez y la Adolescencia (en adelante CNA) establece que "es de aplicación a todos los seres humanos menores de dieciocho años de edad" y a sus efectos define que "se entiende por niño a todo ser humano hasta los trece años de edad y por adolescente a los mayores de trece y menores de dieciocho años de edad", comprendiendo a ambos géneros. Ley $N^{o} 17.823$ del ordenamiento jurídico uruguayo.

2 El artículo 65 del CNA define los órganos de competencia en el caso de los niños y adolescentes estableciendo que "La competencia de los órganos jurisdiccionales en materia de niños y adolescentes es la que fija la Ley No 15.750, de 24 de junio de 1985.

3 Artículo 67. Los Jueces Letrados de Menores entenderán en primera instancia en todos los procedimientos que den lugar a infracciones de adolescentes a la ley penal. En segunda entenderán los Tribunales de Familia. Los actuales Juzgados Letrados de Menores pasarán a denominarse Juzgados Letrados de Adolescentes.

4 El artículo 69 del CNA establece que "son infracciones a la ley penal: 1) Las acciones u omisiones culposas consumadas, cometidas en calidad de autor, coautor, tipificadas por el Código Penal y las leyes penales especiales, cuando el Juez reúna los elementos de convicción suficientes, fundados exclusivamente en el desarrollo de la personalidad psicosocial del infractor; avalado por un equipo técnico, que permita concluir que el adolescente disponía la capacidad cognitiva de las posibles consecuencias de su obrar. 2) La tentativa de infracciones gravísimas a la ley penal. 3) La participación en calidad de cómplice en infracciones gravísimas a la ley penal". 
$\mathrm{te}^{5}$, clasifica los tipos de infracción a la ley penal ${ }^{6}$, establece la adecuación normativa para los casos de las infracciones adolescentes y fija los derechos y las garantías del procedimiento ${ }^{7}$, establece el régimen procesal $^{8}$, las medidas socio-educativas correspondientes a la trasgresión normativa que divide en medidas privativas y no privativas de libertad ${ }^{9}$, el régimen de privación de libertad ${ }^{10}$, los principios de la ejecución ${ }^{11}$, los derechos y deberes durante la ejecución de las medidas socioeducativas ${ }^{12}$, las medidas curativas para los adolescentes incapaces que hubieren cometido infracciones a la ley penal ${ }^{13}$ y la especificación de los procedimientos ${ }^{14}$, comunicaciones ${ }^{15}$ y plazos procesales ${ }^{16}$.

Estas orientaciones legales, sumadas a las disposiciones procesales y la normativa establecida en el Código Penal, serán las regulaciones legales específicas del ordenamiento jurídico uruguayo que, en correspondencia con la normativa internacional, regularán jurídicamente la actuación de los expertos en la justicia de adolescentes.

\section{Resultados}

\section{La infracción adolescente en el proceso judicial montevideano}

A diferencia del resto del país, donde los juzgados concentran una serie de materias en una misma sede, la justicia especializada en adolescentes tiene en la ciudad de Montevideo cuatro sedes judiciales que abordan específicamente la infracción al dere- cho penal protagonizadas por personas que tienen entre 13 y 18 años de edad, denominados Juzgados de Adolescentes.

De acuerdo al Código de la Niñez y la Adolescencia las personas menores de 13 años son considerados niños, por lo que la justicia dispone de sedes judiciales específicas para tratar las infracciones a la ley penal protagonizadas por ellos. Los Juzgados de Familia Especializados, al igual que los Juzgados de Adolescentes, sólo actúan en forma independiente en Montevideo. En el interior del país las infracciones a la ley penal protagonizadas por niños o adolescentes son tratadas por sedes no especializadas.

Montevideo es por tanto la ciudad donde la especialización de la justicia cuenta con los recursos específicos para desarrollar las diferentes materias en lo que tienen de particular, por lo que toda la documentación producida por las sedes judiciales que se analiza en este estudio es específica en la materia. Los expedientes judiciales analizados muestran características formales similares en su forma de procesamiento que se particularizan aún más de acuerdo a la sede que se analice, con formas específicas de actuación de los distintos expertos y funcionarios, que también son pasibles de ser discriminadas en función de la sede judicial.

Las formas de actuación experta se repiten en forma especializada de acuerdo a la sede de que se trate y es posible rastrear modalidades particulares de procesar, de acusar, de defender o de sentenciar.

5 El artículo 70 del CNA expresa: "Se denomina adolescente infractor a quien sea declarado responsable por sentencia ejecutoriada, dictada por Juez competente, como autor, coautor o cómplice de acciones u omisiones descritas como infracciones a la ley penal".

6 En el artículo 71 del CNA se establece que "sólo puede ser sometido a proceso especial regulado por este Código el adolescente a quien se pueda atribuir material y psicológicamente un hecho constitutivo de infracción a la ley penal".

Artículo 72 del CNA. "Las infracciones a la ley penal se clasifican en graves y gravísimas. Son infracciones gravísimas a la ley penal: 1) Homicidio (artículo 310 del Código Penal), 2) Lesiones gravísimas (artículo 318 del Código Penal), 3) Violación (artículo 272 del Código Penal), 4) Rapiña (artículo 344 del Código Penal), 5) Privación de libertad agravada (artículo 282 del Código Penal), 6) Secuestro (artículo 346 del Código Penal), Extorsión (artículo 345 del Código Penal), Tráfico de estupefacientes (artículo 31 y 32 del Decreto-Ley $N^{\circ} 14.294$, de 31 de octubre de 1974, en redacción dada por el artículo $3^{\circ}$ de la Ley $N^{\circ} 17.016$ de 22 de octubre de 1998), 9) Cualquier otra acción u omisión que el Código Penal o las leyes especiales castigan con una pena cuyo límite mínimo sea igual o superior a seis años de penitenciaría o cuyo límite máximo sea igual o superior a doce años de penitenciaría. 10) La tentativa de las infracciones señaladas en los numerales 1), 5) y 6) y la complicidad en las mismas infracciones. En los casos de violación no se tomará en cuenta la presunción del ejercicio de la violencia (artículo 272 del Código Penal) Las restantes son infracciones graves a la ley penal.

7 Artículo 74 del CNA.

8 Artículos 75 y 76 del CNA.

9 Artículo 77 a 88 del CNA.

10 Artículo 89 del CNA.

11 Artículos 99 a 101 del CNA.

12 Artículo 102 del CNA.

13 Artículo 106 del CNA.

14 Artículos 108 a 110 del CNA.

15 Artículos 111 a 114 del CNA.

16 Artículo 115 del CNA. 
Los expedientes judiciales dan cuenta del debate argumental de los expertos en derecho en el marco de un intercambio regulado por las disposiciones jurídicas que establecen las formalidades del procesamiento judicial. El análisis de estos discursos muestra la existencia de acuerdos implícitos en relación a la exposición de los hechos que se realiza en el marco del auto de procesamiento, cuyo origen es posible rastrear hasta el sistema policial, retomado tanto en el marco de la acusación fiscal como en la relación de hechos realizada en el escrito de la sentencia.

El debate de los expertos en el procesamiento judicial parece estar centrado primordialmente en dos aspectos: la dilucidación referente a la calificación jurídica de la infracción y las medidas planteadas en forma de prevención o sanción.

Dado el acuerdo general en relación a la exposición de los hechos que se relatan en el auto de procesamiento, si bien la calificación jurídica de la infracción analizada puede dar lugar a intercambio argumental, es el carácter de la sanción y la determinación de su duración lo que genera el debate más recurrente en el marco del procesamiento judicial.

En este aspecto, la discusión central se plantea en relación a la determinación o no de una medida privativa de libertad, tanto en referencia a la medida cautelar como en relación a la medida de sanción. En este sentido, es posible observar que el carácter de la medida cautelar dispuesta tiene una influencia determinante sobre la discusión en relación al carácter de la medida de sanción. En este sentido, si se dispone una medida cautelar privativa de libertad al inicio del procesamiento, es probable que se determine una sanción de estas características en la sentencia. Lo mismo sucede cuando se determina una medida cautelar de carácter alternativo a la privación de libertad.

Cuando existe acuerdo entre el ministerio público y la defensa acerca del carácter privativo o no privativo de libertad de la sanción a imponer, el debate se centra en el tiempo de duración de la medida, confrontación que se resuelve en el escrito de sentencia. Tanto la ejecución de la medida cautelar como la implementación de la medida de sanción dispuesta en el marco del procesamiento son monitoreadas por el sistema judicial a través de informes técnicos especializados, que dan cuenta del cumplimiento de las medidas de control.

Los documentos de la muestra analizada señalan el carácter directriz del sistema judicial en el análisis de la conducta infractora protagonizada por los adolescentes y su influencia directa sobre las insti- tuciones responsables de la ejecución de la sanción dispuesta. No obstante la rectoría que la institución judicial marca respecto a la ejecución penal, los expedientes estudiados dan cuenta de cierta influencia de las instituciones penales sobre el sistema judicial, que invierte la dirección señalada. En este sentido, los documentos judiciales señalan la receptividad del sistema judicial frente a los planteos expertos surgidos en el contexto institucional del sistema de ejecución de medidas socioeducativas.

En el contexto de este debate argumental -planteado a nivel jurídico-acerca de las medidas de control y de sanción que corresponden a la infracción que se analiza en el proceso judicial, se reconoce la influencia que la consideración de las características socioeconómicas y vinculares de la familia del adolescente tienen sobre el juicio de los expertos en derecho a la hora de evaluar el tipo de medida judicial que en cada caso corresponde. En este sentido, el análisis documental muestra que la evaluación de este tipo de factores contextuales tiene mayor peso relativo que la calificación jurídica de la infracción en el momento de la determinación del carácter privativo de libertad de la medida a adoptar. Esta constatación empírica abre el debate jurídico, recurrentemente planteado a nivel nacional, acerca del derecho que coloca el acento en el autor de la infracción en lugar de evaluar jurídicamente la conducta trasgresora.

Sugeridas como medida de excepción en el Código de la Niñez y la Adolescencia, la privación de libertad en la adolescencia es utilizada por el sistema judicial como medida de protección social en situaciones familiares críticas, de forma relativamente independiente a la gravedad de la conducta que origina la sanción. En el marco del sistema judicial uruguayo la privación de libertad parece ser utilizada como un dispositivo disponible de política social que sustituye la carencia de este recurso en el área de la infancia y la adolescencia como medida de protección social.

Esta captación de adolescentes socialmente desprotegidos por parte del sistema judicial supone la disposición de medidas de control social en casos de ausencia de políticas de seguridad social. De esta forma, en Uruguay la política de seguridad pública viene a sustituir a la política de protección social.

Empleadas con el argumento de la protección de los derechos de la infancia y la adolescencia, las medidas socioeducativas dispuestas por el sistema judicial representan un castigo a la infracción protagonizada por adolescentes, con las consecuencias estigmatizantes sobre la vida de las personas que la aplicación 
de un dispositivo de control social implica.

La intervención pública frente a las situaciones de vulnerabilidad en la infancia y la adolescencia aparece en el momento de la trasgresión adolescente y se hace presente desde una medida de control.

La internación del adolescente que comete una infracción parece ser la respuesta del Estado a esta situación de desamparo que contextualiza la trasgresión normativa en conductas que atentan contra los derechos de las personas o ejercen una forma de violencia que impresiona como injustificada frente a una víctima inocente.

Ya sea en el escenario judicial como en el de la institución que tiene a cargo la ejecución de las medidas socioeducativas respecto a la infracción, aparece la figura de nuevos especialistas del área educativa, social o psicológica que intentan vincular la trasgresión con la historia personal y social del adolescente que comete un acto infraccional.

\section{Discusión}

\section{El discurso pericial en la justicia penal adolescente y en el sistema de ejecución de medidas socioeducativas}

Planteados desde espacios disciplinares distintos al estrictamente jurídico, este tipo de discursos expertos centran su atención en el adolescente, describiendo etapas significativas en su proceso de socialización, su vinculación al sistema educativo, a espacios sociales y recreativos, analizando también sus vínculos sociales más cercanos. El peritaje social y psicológico plantea posibles hipótesis explicativas que vincula la infracción a la vida y a la familia del adolescente ${ }^{17}$.

En los informes producidos en el ámbito penal el enunciado del riesgo social parece sintetizar la descripción de una situación familiar y social marcada por la carencia material y simbólica de bienes socialmente apreciados en la valoración del bienestar social. Los diagnósticos de riesgo social enumeran consecuentemente dificultades en el plano de la obtención de empleos calificados, socialmente reconocidos y protegidos, en el tránsito por el sistema educativo, en el acceso a bienes culturales, y en el desarrollo de redes de relaciones sociales estables, plurales y diversas.

Mediante el enunciado del riesgo social, los peritajes proceden a la enumeración de los indicadores sociales que señalan las carencias en los satisfactores de necesidades sociales indispensables para el bienestar sustentados en el señalamiento de limitaciones en el plano personal y familiar para la generación de condiciones de vida satisfactorias.

El diagnóstico de riesgo social de una familia hace referencia, en primer lugar, a las posibilidades del adecuado desempeño de las funciones paternas, que son evaluadas por los expertos a través de la entrevista con el adolescente. En riesgo social se encuentran pues, con matices, aquellos adolescentes con una familia "desintegrada", con "dificultades vinculares", que no logró apoyar la culminación del sistema educativo primario de sus hijos adolescentes, que no proporcionó la contención necesaria para evitar la situación de calle, el consumo problemático de sustancias psicoactivas, la venta callejera, la mendicidad, la prostitución, la maternidad adolescente, o que tiene antecedentes sanitarios relacionados con la salud mental, el alcoholismo, la privación de libertad, o la violencia en sus vínculos.

En segundo término, los expertos relacionan el riesgo social a las posibilidades socio-ambientales, económicas y culturales del entorno social inmediato. En este sentido se hace referencia a la situación social y sanitaria de la vivienda, a las condiciones socioeconómicas de la familia primaria y extensa, a las dificultades laborales de los adultos referentes, al control sanitario, a la situación educativa del adolescente, sus hermanos y otros niños a cargo de los padres, al analfabetismo y nivel educativo y cultural de los adultos, al capital social y cultural del entorno familiar, en última instancia, a la situación de pobreza de la familia.

Los adolescentes en situación de riesgo social son, en definitiva, los pobres. Con el diagnóstico de riesgo se enuncia la situación de pobreza en lo que refiere al capital simbólico, social, cultural y económico de la familia de origen y de referencia de los adolescentes.

Este tipo de lectura microsocial, que centra su mirada en el individuo, señalando tanto sus dificultades como sus potencialidades en la movilización de recursos propios y sociales para la obtención de metas de bienestar social aceptadas, coloca en los factores individuales la explicación del fenómeno de la pobreza. Si el análisis microsocial de las situaciones de pobreza es pensado en términos de factores individuales de explicación, la consecuencia del planteo

17 Siguiendo la influencia de la criminología crítica, Carlos Uriarte lee este esquema de interpretación de las causas de la infracción desde el paradigma de la criminología clásica, que busca explicar la etiología del delito como comportamiento anómalo (1999, 2006). 
es la responsabilización individual por la situación en que se encuentran estos sectores sociales.

En los discursos periciales se describen familias con severos problemas en la provisión y cuidado de sus miembros, abandonadas a la construcción de estrategias de supervivencia informales, sin las protecciones sociales derivadas del trabajo en condiciones de estabilidad y formalidad. En este sentido, los informes que evalúan el riesgo social de las situaciones soci o-familiares en observación, parecen situarse en el esquema de la concepción tutelar que partía de la mirada de la "situación irregular" de "los menores abandonados" cuyo tránsito natural los llevaría a la delincuencia (Erosa e Iglesias, 2000; García Méndez, 1994, 2004; Uriarte, 1999, 2006).

Leídos en el contexto de la implementación de medidas judiciales de respuesta ante la infracción normativa, el diagnóstico de riesgo respecto a los adolescentes evaluados en el ámbito penal puede adquirir un sentido contextual específico. En este marco, la lectura experta del riesgo que realizan los peritos activa una alarma social frente al sistema judicial que, retomando el análisis de los especialistas, adopta medidas concretas para fortalecer los mecanismos de defensa social como respuesta.

En el contexto de la infracción adolescente, la evaluación experta de riesgos sociales sugiere la implementación de medidas de control social más estrictas ante la amenaza. Considerando el marco normativo nacional del cual emerge -en el área de la justicia adolescente- el diagnóstico de riesgo sugiere, como en la doctrina tutelar ante la infancia pobre, la respuesta de la institucionalización (Platt, 1982; Morás, 1992; García Méndez y Carranza, 1992; García Méndez, 1994; Costa y Gagliano, 2000).

Recogida en un nuevo discurso, la imagen paradigmática del "menor abandonado y delincuente" parece corresponderse casi exactamente con el sentido de alarma social atribuido al diagnóstico del riesgo de los ahora llamados "adolescentes infractores". La respuesta social a aquella descripción, resemantizada como medida socioeducativa en el discurso contemporáneo de la protección integral a la infancia, es nuevamente, la internación.

Lejos de oficiar como elemento que contextualiza la infracción adolescente, la situación social de pobreza parece plantear una alarma frente al riesgo, activando los mecanismos de la defensa social que recurren al encierro de los elementos peligrosos.

Si bien parecen describir situaciones personales y familiares mediante un lenguaje especializado de carácter científico, las palabras utilizadas por el discurso experto de la pericia remiten a ciertos contenidos morales con poder sancionatorio de ciertas actitudes y conductas que aparecen teñidas con características de "perversión" o de "anormalidad", para utilizar las categorías conceptuales que emplea Foucault. Utilizadas en el discurso de la pericia, estas características de perversión o anormalidad en la descripción de la situación individual y familiar del adolescente le otorgan un sello de distinción que, mediante el juicio de la infracción cometida, lo invisten de peligrosidad.

Enmarcada en esta doble función de detectar el peligro, la pericia se convierte en un discurso del miedo al peligro frente al que opone un discurso de la moralización. El discurso especializado de la pericia se inviste con una serie de categorías de orden moral que parecen retraducir el discurso técnico del lenguaje experto (Foucault, 2000).

El análisis experto sobre la biografía del adolescente bajo la forma de peritaje psicológico o social remite a la intrusión de discursos de reparación terapéutica en el sistema de control y castigo que describe Foucault a finales del siglo XIX y durante el siglo XX (Foucault, 2000). Se trata de un saber de reparación unido a un discurso de control de la conducta que influye sobre la vida de la persona, reorientándola hacia un cambio personal con eje en la experiencia social.

\section{La concepción reflexiva de la autonomía individual y la responsabilidad individual en el éxito y el fracaso}

Para Beck (1994) y Giddens (1994, 1995), la modernidad reflexiva, cuyo proceso de materialización social avanza inadvertidamente para los actores implicados, tiene consecuencias significativas en la forma en que estos se relacionan con las instituciones sociales y con los sistemas abstractos que las fundamentan y legitiman. Esta nueva forma de relaciones entre los actores y la estructura social que los analistas señalan, se genera en un contexto de reflexividad social que aumenta las posibilidades de diálogo de los agentes con los sistemas abstractos, brindándoles una mayor posibilidad de crítica y de distanciamiento respecto a los mecanismos sociales que condicionaran sus decisiones y sus cursos de acción en las sociedades tradicionales y durante la primera la modernidad.

De acuerdo a los autores de la modernidad reflexiva, esta mayor independencia respecto a las constricciones estructurales, a la vez que aumenta 
las posibilidades de libertad, genera nuevas incertidumbres y nuevos temores, exponiendo a los agentes a nuevos riesgos. La evaluación de los riesgos de vivir en una época de cambios vertiginosos e imperceptibles se transforma en un asunto social de interés relevante.

Se abre así un campo infinito de posibilidades para la toma decisiones sobre la acción individual en un terreno minado por la incertidumbre y el riesgo. Surgen en este contexto, infinidad de discursos expertos que informan a los legos de las probables consecuencias de asumir uno $\mathrm{u}$ otro camino en torno a las múltiples decisiones a adoptar en la vida diaria de las sociedades contemporáneas características de la modernidad tardía. En sus análisis de la década del noventa, Giddens $(1994,1995)$ describe con preocupación los efectos de la intrusión de estos sistemas expertos en la vida cotidiana de los individuos, no sin admitir el alivio que la información experta supone para las decisiones individuales.

Convenientemente informado por los sistemas expertos de la modernidad tardía, el individuo se expone a la responsabilidad de las consecuencias de decisiones asumidas en contextos reflexivos que suponen cada vez mayores márgenes de libertad (Giddens, 1994, 1995).

El incremento en las posibilidades de libertad individual genera procesos de individuación más amplios y más radicales en sus consecuencias que aquellos que la modernidad simple habilitara por medio de la liberación individual frente a las estructuras de la sociedad tradicional. De esta manera, el individuo se reconoce libre frente a la posibilidad de diseñar su biografía a la medida de sus motivaciones e intereses, que modifica y transforma a la vez que cambian sus inquietudes en las distintas etapas de su trayectoria de vida. En el mismo sentido en que cambian sus preferencias y orientaciones, se modifican también sus compromisos y sus redes de relaciones, ampliando, restringiendo o transformando sus pertenencias y las elecciones personales respecto a las influencias sociales que recoge o desestima (Beck, 1994).

En este tipo de sociedad crecientemente reflexiva y autocrítica que describen los teóricos de la individualización positiva, la identidad es una construcción de autodiseño, en la que poco influyen las estructuras sociales donde se desplegaba el teatro social de la modernidad simple y donde el individuo, libre de construcciones sociales limitantes, depende solo de sí mismo.

Convenientemente informado por sistemas abs- tractos que operan en todos las esferas sociales y se intercalan en todas los aspectos de la vida cotidiana, el individuo es colocado ante el riesgo de sus propias decisiones y deberá asumir las responsabilidades implicadas en sus consecuencias.

Los analistas de las sociedades contemporáneas de los países centrales suponen un contexto de reflexividad institucional en aumento, que otorgaría cada vez mayores niveles de autonomía a las decisiones individuales informadas por estos sistemas abstractos de actividad refleja. En contextos sociales reflexivos, la acción individual se supone ella misma también reflexiva, con posibilidad de transformación y adaptación a circunstancias sociales que cambian vertiginosamente.

En el supuesto de igualdad de posibilidades en el acceso a la información experta respecto a la multiplicidad de decisiones que la vida contemporánea supone, la búsqueda de orientación experta en relación a la propia vida corresponde a los interesados. En este sentido, por ejemplo, los futuros padres deben buscar atención experta respecto a los necesarios cuidados requeridos en relación a la concepción, el embarazo, o el parto, así como la orientación de especialistas respecto a las pautas de crianza durante todas las etapas del desarrollo del niño hasta su vida adulta y, aún después de la independencia de los hijos, frente a los desafíos que cada nueva etapa de la vida de padres plantea.

Las decisiones libres de los individuos deben ser convenientemente informadas por sistemas abstractos especializados, pero una vez adoptadas, corresponde al individuo el asumir las consecuencias que de ella se deriven.

En una lectura que no interpreta a la pobreza como constreñimiento estructural a las vidas de los individuos, los diagnósticos de evaluación de riesgos que las pericias proponen, parecen partir del supuesto de la independencia de las decisiones individuales.

En este sentido, las decisiones respecto a la propia preparación para la competencia en el mercado laboral, en relación a la formación de la familia, la cantidad de hijos, su educación, su orientación en el proceso de socialización y adquisición de competencias sociales, el cuidado de su salud y la elección del sistema de coberturas sociales frente a los riesgos, corresponde al individuo. Desde este supuesto, la responsabilidad respecto a las consecuencias que estas decisiones plantean, es también individual.

Sin embargo, considerando los supuestos de la evaluación de riesgo, cabría preguntarse si estas familias pobres en capital social, económico y cultural 
pueden ser valoradas en ausencia de los condicionamientos estructurales.

Beck no desconoce que en esta tercera fase de la modernidad que está analizando, "crecientes círculos de población son excluidos en la modernidad de las condiciones de existencia y de las redes de seguridad de la modernidad" (Beck, 2001, p.21).

La lectura normalizadora de la vida individual, en la que se sustentan los informes expertos derivados del ámbito judicial e institucional de control, en la que la carga está puesta "sobre los hombros del individuo", puede ser relativizada tanto mediante la lectura contextualizada de Beck como a partir de las afirmaciones de Bauman.

No es que parezca que las "soluciones biográficas" sean gravosas y penosas: simplemente no existen "soluciones biográficas a contradicciones sistémicas" que resulten efectivas, y entonces la escasez de soluciones viables disponibles debe ser compensada con soluciones imaginarias. (Bauman, 2000: 44).

Este tipo de lectura cambia la perspectiva del análisis de la responsabilidad. En el análisis en de la modernidad reflexiva, la experiencia de la autonomía individual nace en un contexto histórico de aseguramiento y protección social. Poner el énfasis las condiciones sociales necesarias para el desarrollo de un individuo autónomo y por tanto responsable de decisiones libres implica la construcción de dinámicas sociales de habilitación individual.

En este sentido, si los procesos sociales no contribuyen a construir ciudadanía autónoma, asegurando las condiciones de bienestar social, las alternativas individuales aparecen sesgadas por las limitaciones estructurales.

Si se pone el foco en las condiciones sociales que favorecen o limitan el desarrollo individual, es preciso analizar las responsabilidades compartidas por la desprotección social de algunos miembros de la sociedad que inhiben su desarrollo autónomo.

Esta afirmación parece contribuir al debate de la responsabilidad social en la formación de seres humanos que nacen y crecen en condiciones de desprotección, que no son habilitados al aprendizaje de las normas de una convivencia social estimulante al desarrollo individual. En este contexto podrían ser explicadas las conductas agresivas o lesivas de derechos protagonizadas por estos "in- dividuos por defecto," para utilizar la expresión de Castel $(2010)^{18}$.

\section{El recurso a la noción de vulnerabilidad social en los discursos técnicos}

La confrontación argumentativa en torno a los temas de estudio constituye el marco en que se desarrollan las aproximaciones al objeto de trabajo de la ciencia. En función de concepciones del mundo y tradiciones de pensamiento diferenciadas, los especialistas ensayan distintas interpretaciones sobre los fenómenos que estudian, produciendo discursos diversos en relación a los mismos temas. Decía que, en el contexto de la modernidad tardía, la ciencia pierde la inocencia que produjera explicaciones totalizantes, socialmente valoradas y recogidas como verdades científicas irrefutables (Beck, 1997: 22). Esta confrontación de explicaciones sobre los asuntos sociales puede darse en forma explícita o solapada entre los expertos que abordan un mismo objeto de conocimiento.

El análisis situacional que se plantea en los marcos institucionales del sistema penal, también sugiere acercamientos expertos diferenciados en torno a los mismos asuntos.

La aproximación experta a la infracción adolescente de los especialistas que trabajan en las instituciones penales, considera, como ya se ha señalado, al individuo en su contexto familiar y entorno social más cercano, analizando su trayectoria biográfica en este escenario.

Dado que la mayoría de los adolescentes que transitan por las instituciones penales pertenecen a sectores sociales desfavorecidos, la lectura del contexto social en el que desarrollan sus vidas, lleva implícita una aproximación al fenómeno de la pobreza. En este sentido, la descripción situacional que realizan los expertos se centra en constatar las fragilidades sociales en materia de acceso a satisfactores relacionados con el mundo del trabajo, la educación, la salud, la vivienda o los vínculos sociales.

Sin embargo, la lectura de la pobreza como vulnerabilidad social cambia el énfasis situado en las dificultades experimentadas por los individuos y sus grupos familiares para el acceso a ciertos bienes sociales.

Por el contrario, esta lectura está centrada en las limitaciones que el sistema de protección social experimenta en el cumplimiento de la función de

18 Los esfuerzos por argumentar en este sentido han fundamentado la corriente de la criminología crítica a la que puede reconocerse un desarrollo histórico no lineal desde la década del sesenta del siglo XX (Larrauri, 1991). 
proporcionar los satisfactores adecuados a las necesidades básicas de estos grupos familiares.

Esta mirada hacia los derechos sociales desprotegidos de los sectores sociales vulnerables, parece situarse en el sistema de garantías socialmente exigibles para el desarrollo individual y familiar. En este sentido, la aproximación de estos informes expertos al tema de la pobreza, parece ubicar las causas del fenómeno en las fallas en el sistema de protecciones sociales que el Estado debería asegurar a los miembros de la sociedad que quedan excluidos de los sistemas sociales de producción y distribución de la riqueza socialmente generada.

Si la mirada sobre las carencias de estos grupos familiares está puesta en las fallas del sistema de protecciones sociales, la postura teórica de estos informes parece suponer una mayor vinculación del desarrollo individual respecto a la estructura de oportunidades sociales.

Estos análisis situacionales parecen partir de una concepción distinta a la del individuo libre de condicionamientos sociales, cuya búsqueda de información en los sistemas abstractos de las sociedades reflexivas garantizaría la colonización de un futuro abierto a nuevas oportunidades en contextos de riesgo.

La lectura de las condiciones sociales de la vida de estos individuos vulnerables parecería proporcionar hipótesis explicativas respecto a sus trayectorias biográficas, en una mirada de sus decisiones y conductas que parece estar interpretada a partir de limitaciones impuestas por los condicionamientos sociales de sus posibilidades de elección.

En estas hipótesis explicativas de las conductas individuales, las situaciones de pobreza son analizadas como limitaciones estructurales a la libertad de decisión en una gama de opciones que no parecería estar abierta y disponible para todos los miembros de la sociedad.

Este posicionamiento teórico en relación a los condicionamientos sociales de la elección individual, también supone una postura distinta respecto a la responsabilidad individual en torno a la infracción adolescente.

Si la lectura de las vulnerabilidades sociales de estos individuos y sus grupos familiares se coloca en las debilidades del sistema de protecciones sociales para garantizar los derechos individuales, la responsabilidad en torno a las decisiones adoptadas en contextos de restricción social, estableciendo las mediaciones que la interpretación de las acciones individuales supone, es también social.
En este sentido, la mirada experta sobre la responsabilidad individual en la infracción adolescente explicada en contextos de pobreza y falta de garantías sociales, debería ser socialmente relativizada en atención a la coresponsabilidad social en la protección de los derechos de estos miembros vulnerables de la sociedad.

Aparentemente inocente, la elección del concepto de vulnerabilidad social en la descripción de las situaciones familiares de los adolescentes que transitan por el sistema penal, parece significar una toma de posición respecto a los condicionamientos sociales de la acción y por lo tanto de las responsabilidades colectivas en relación a la infracción.

Esta lectura de los condicionamientos sociales de una conducta desarrollada en el contexto de las limitaciones que impone la pobreza implica también una toma de posición respecto a la exigibilidad en la protección de los derechos sociales. Este marco de interpretación supone además un tratamiento diferente respecto a la sanción social que se impone como respuesta colectiva a estas conductas.

Construido desde el supuesto de un individuo libre de condicionamientos sociales que ofende, con su infracción a las normas, las bases de la convivencia social regulada, el paradigma de la defensa social se coloca desde la exigibilidad social de la reparación de la ofensa. La respuesta social del encierro de estos transgresores se plantea así, únicamente desde la responsabilidad que cabe al individuo por su conducta.

La resignificación de la mirada responsabilizante del riesgo que la lectura de la vulnerabilidad social de los infractores plantea, recurre a la idea de la asunción de la corresponsabilidad social en estas trasgresiones y supone también, una respuesta social diferente frente a la trasgresión.

El reconocimiento de la falta de garantías colectivas para el desarrollo de los derechos sociales de estos individuos plantea la necesidad de la reparación social ante la desprotección. En este sentido, la detección experta de la fragilidad social de los adolescentes debería implicar una respuesta social organizada que garantice estos derechos vulnerados. En este marco de interpretación, la vulnerabilidad social de los infractores debería responderse mediante mecanismos que aseguren la protección social de los adolescentes y sus grupos familiares.

El establecimiento de un sistema de garantías sociales para la protección de los grupos sociales más vulnerables debería estar centrado en el fortalecimiento de los mecanismos protectores que la 
sociedad dispone para promover el desarrollo de las potencialidades individuales y sociales de estas familias. La respuesta del aislamiento institucionalizador de los adolescentes parece dirigirse en sentido contrario a esta apuesta por la protección social de la vulnerabilidad señalada por los expertos en sus informes.

La institucionalidad del sistema penal en la que surgen estos diagnósticos que detectan la vulnerabilidad social de los adolescentes resulta un marco adecuado -no el único, ni el mejor-para plantear la exigibilidad social en el cumplimiento de las garantías sociales de protección de los derechos vulnerados. Dirigidos al sistema judicial, estos informes plantean un incumplimiento de los deberes sociales del Estado en proporcionar las condiciones adecuadas para el desarrollo de sus miembros. La respuesta del sistema judicial frente a esta denuncia, no puede ser otra que la de exigir al Estado la reparación frente a este incumplimiento.

En este sentido, el análisis de las categorías que los expertos utilizan en sus diagnósticos, replantea la lectura social frente al tema de la trasgresión normativa y sugiere nuevas respuestas sociales para su atención y tratamiento.

\section{Consideraciones finales}

\section{Las consecuencias sociales del peritaje en los contextos judicial y penal}

Los sistemas expertos desarrollan sistemas de medición y categorización que se apoyan en la precisión de los problemas a los que deben prestar solución. Esta capacidad de delimitar con exactitud los asuntos conduce a la hiperespecialización experta. Este fenómeno tiene, como uno de sus efectos, el alejar el conocimiento especializado de los afectados, distanciando las posibilidades de que los realmente involucrados en los problemas sujetos a consideración experta sean capaces de evaluar y prever las consecuencias del aporte de información más allá del contexto concreto en que se aplica (Giddens, 1995).

Esta ajenidad en el empleo de los contenidos de la información proporcionada por los sujetos de parte del experto deja al profano en situación de indefensión frente a las consecuencias no deseadas e imprevistas del uso de esta información. En el caso de los sistemas judicial y penal, la utilización de la información que brinda el adolescente en el ámbito reservado de la entrevista con el perito judicial o los técnicos responsables del cumplimiento de medidas de prevención y punición es expuesta en el expe- diente judicial y reinterpretada por otros expertos, con sofisticación tal que la vuelve irreconocible para el propio productor de la información.

El peritaje experto en este contexto tiene consecuencias sociales. Por un lado, el dictamen pericial genera consecuencias punitivas en la vida de los propios afectados, oficiando como mecanismo de evaluación de riesgos futuros mediante la evaluación de las características individuales y sociales de los individuos analizados. Por otra parte, la evaluación de los riesgos sociales de las situaciones que se colocan ante la observación del perito tiene consecuencias sociales que trascienden las institucionales. En el caso de la infracción adolescente, la alarma se enciende desde el sistema judicial. La respuesta social en este contexto no puede darse a partir de la protección social sino de la sanción, que no es sino la respuesta socialmente organizada frente a una alarma de riesgo. En este contexto, el diagnóstico de riesgo social aparece como un llamado de atención para la activación de los mecanismos de defensa social.

El riesgo social implica peligro, despierta la alarma, activa la respuesta que resulta ser la aplicación de la privación de libertad para los adolescentes cuyas conductas infractoras han sido explicadas por los informes periciales, en función de deficitarios procesos de socialización y déficit familiares de continentación. La contención social se organiza, pues, socialmente; la respuesta es institucional. El resultado, sin embargo, no resulta en protección social frente al desamparo, sino que, a partir de la institucionalización vía judicial, las consecuencias sociales resultan en procesos de estigmatización del adolescente mediante la implementación de mecanismos de control social de carácter sancionatorio.

\section{Referencias bibliográficas}

BECK, U. (1994) "Teoría de la sociedad de la modernización reflexiva", en Las consecuencias perversas de la modernidad: modernidad, contingencia y riesgo. J. Beriain (comp.) Barcelona, Anthopos, 223-265.

BECK, U. (1997) "La reinvención de la política: hacia una teoría de la modernidad reflexiva ", en Beck, U., Giddens, A y Lash, S. Modernización reflexiva. Política, tradición y estética en el orden social moderno. Madrid, Alianza Universidad, 13-74.

BECK, U. (2001) "Vivir nuestra propia vida en un mundo desbocado: individuación, globalización y política", en Giddens, A. y Hutton, W. (eds.) En el límite. La vida en el capitalismo global. Barcelona, Kriterios TusQuets Editores. 
BERGER, P. Y LUCKMANN, T. (1972) La construcción social de la realidad. Buenos Aires: Amorrortu.

CASTEL, R. (2010) El ascenso de las incertidumbres. Trabajo, protecciones, estatuto del individuo. Buenos Aires: Fondo de Cultura Económica.

Código de la Niñez y la Adolescencia (2004) Ley No 17.823. Montevideo: Poder Judicial.

COSTA, M. Y GAGLIANO, R. (2000) "Las infancias de la minoridad", en Duschantzky, S. (comp.) Tutelados y asistidos. Programas sociales, políticas públicas y subjetividad. Buenos Aires, Paidós.

EROSA, H; IGLESIAS, S. (2000) La construcción punitiva del abandono. Montevideo. Serie materiales de apoyo. CENFORES. INAU.

FOUCAULT, M. (2000) Los anormales. Buenos Aires: Fondo de Cultura Económica.

GARCÍA MÉNDEZ, E. (1994) Derecho de la infanciaAdolescencia en América Latina: de la Situación Irregular a la Protección Integral. Santa Fe de Bogotá. Ediciones Forum Pacis.

GARCÍA MÉNDEZ, E. Y CARRANZA, E. (1992) Del Revés al Derecho. La condición jurídica de la infancia en América Latina. Bases para una Reforma Legislativa. Buenos Aires. Editorial Galerna. UNICEF. UNCRI. ILANUD

GARCÍA MÉNDEZ, E. (2004) Infancia de los derechos y de la justicia. Buenos Aires. Ediciones del Puerto.

GIDDENS, A. (1994) Consecuencias de la modernidad. Madrid. Alianza Editorial.

GIDDENS, A. (1995) Modernidad e identidad del yo. Barcelona. Península.

GONZÁLEZ, C. Y LEOPOLD, S. (2011) Discurso del riesgo y prácticas diagnósticas con niños y adolescentes en el ámbito socio-judicial. Montevideo. CSIC-UdelaR.

MORÁS, L.E. (1992) Los hijos del Estado. Montevideo. DS. FCS. UDELAR-SERPAJ.

PLATT A. (1982) Los "Salvadores del Niño" o la invención de la delincuencia. México, Siglo XXI.

URIARTE, C. (1999) Control institucional de la niñez adolescencia en infracción. Un programa mínimo de contención y límites jurídicos al Sistema Penal Juvenil (las penas de los jóvenes). Montevideo. Carlos Álvarez Editor.

URIARTE, C. (2006) Vulnerabilidad, privación de libertad de jóvenes y derechos humanos. Fundación de Cultura Univerfsitaria, Uruguay. 